\title{
Understanding the mobilised oil drainage dynamics inside laboratory-scale and field-scale reservoirs for more accurate THAI process design and operation procedures
}

\author{
Muhammad Rabiu Ado ${ }^{1}$ (D)
}

Received: 26 July 2021 / Accepted: 30 August 2021 / Published online: 12 September 2021

(c) The Author(s) 2021

\begin{abstract}
The technical and economic validities of the toe-to-heel air injection (THAI) process for heavy oils upgrading and production are yet to be fully realised even though it has been operated at laboratory, pilot, and semi-commercial levels. The findings from Canadian Kerrobert THAI project suggested that there is no proportionality between oil production and air injection rates. However, this conclusion was reached without having to dig deeper into the dynamics of the transport processes inside the reservoir especially that efficient combustion was clearly taking place as the mol\% oxygen in the produced gas was negligible. As a result, this study is conducted with aims of identifying the similarities and differences of the dynamics of the transport processes in lab-scale and field-scale reservoirs. For the first time, this study has found oil drainage dynamics inside the reservoir to be both scale-dependent and operation-dependent. For the laboratory-scale numerical model E, what is clearest is that all of the head of the oil flux vectors are either totally vertically directed or slightly inclined and pointing upward towards the heel. None of them is pointing backward towards the toe of the HP well. Thus, it is apparent that oil drainage pattern in this laboratory-scale model E is efficient as all the mobilised upgraded oil, including from the base of the combustion cell, is produced as the combustion front advances in the toe-to-heel manner. However, the combustion front has a backward-leaning shape which is an indicator that it is propagating even inside the HP well. This implies that the process is operating in an unstable, inefficient, and unsafe mode. These two opposing patterns at laboratory-scale must be resolved to ensure healthy combustion front propagation with efficient oil drainage and production rates are achieved. At the field scale (i.e. model F), this study has shown for the first time that there are actually two mobile oil zones: the one ahead of the combustion front with lower oil flux magnitude (i.e. MOZ) and the one containing large pool of mobilised partially upgraded oil at the base of the reservoir just behind the toe of the HP well. The above findings in model $\mathrm{F}$ show that there is conflicting dynamics about the goal of achieving large oil production rates downstream of the combustion front with the propagation of forward-tilting stable, safe, and efficient combustion front. If the combustion is to be optimally sustained, then most of the mobilised upgraded oil might be lost going in the wrong direction towards the region behind the toe of the HP well. In actual reservoir in the field, shale with very low permeability and porosity must be present behind the toe in order for the large pool of mobilised upgraded oil that is continuously draining from the vertical adjacent planes to be forced into the toe of the HP well. As a result, to balance these two conflicting dynamics of upward-tilted combustion front going longitudinally towards the heel of the HP well and the mobilised oil draining down at an angle towards the region behind the toe of the HP well, future studies are essentially required. These are proposed and also listed under the conclusion section in order to ensure thorough design and operation procedures for the THAI process are established.
\end{abstract}

Keywords In situ combustion (ISC) · Enhanced oil recovery (EOR) · Heavy oil/bitumen/tar sand · Reservoir simulation . Toe-to-heel air injection (THAI) $\cdot$ Thermal EOR

Muhammad Rabiu Ado

mado@kfu.edu.sa

1 Department of Chemical Engineering, College of Engineering, King Faisal University, P.O. Box: 380, Al-Ahsa 31982, Kingdom of Saudi Arabia

\section{Introduction}

No doubts that the world is transitioning to a decarbonised future even though no one knows how long it will take to reach there. Since it is not a step change, the readily available resources are essential for a smoothest transition. Although 
technology is evolving rapidly and that the energy sector is seeing one of the fasted move towards greener future, there are certain sectors such as transportation and petrochemical that do not have substitute for a faster switch. Thus, oil and gas must continually be accessible to cater for the surging demand especially from the highly populated developing countries. However, accessible oil might not last long enough to see us to the fully carbon-free energy system era unless continual research and development of the currently non-producible reserves are sustained. Based on the United States Geological Survey (USGS) report, there are around 8.901 trillion barrels of unexploited heavy oils and bitumen around the globe (Meyer et al. 2007). Most recent estimates conducted by the China National Petroleum Corporation (CNPC) put the total amount of heavy oils and bitumen globally as 1492.44 billion tonnes of oil originally in place (OOIP). However, the world-wide total recoverable reserves based on our present technological know-how is only 190.87 billion tonnes of OOIP (Liu et al. 2019). According to the BP's statistical review of world energy 2020, as at the end of 2019 , the world-wide total proven reserves of conventional and unconventional oils is 244.6 billion tonnes (British Petroleum (BP) 2020). However, the proven reserves of light conventional oils total to 53.73 billion tonnes only which surely will not be enough to last until fully decarbonising our energy system. That implies that heavy oils and tar sands reserves must be immediately developed to ensure a smooth supply is maintained. However, these resources are known to have very high viscosities and low API gravities which are determined by their asphaltene content. As a result, they are very difficult, environmentally polluting, and expensive to tap. Yet the applied commercial mobilisation and production methods are steam-based. These include steam flooding, cyclic steam stimulation, and the most popular method, namely steam-assisted gravity drainage, and they are characterised of: (i) having low energy efficiency due to significant heat losses to the wellbore, overburden, and underburden, (ii) not effecting permanent upgrading since once the produced oil is cooled back to its initial reservoir temperature, its viscosity and density will increase and return back to their initial values, (iii) being applicable to limited number of reservoirs due to pressure limitations when the reservoir is thin, (iv) emitting large amount of greenhouse gases from the steam generation, (v) requiring complex surface upgrading facilities, (vi) in certain cases, being net energy consumer as the produced chemical energy is less than the thermal energy added, etc., (Gates 2010; Gates and Larter 2014; Ma and Leung 2020; Mokrys and Butler 1993; Paitakhti Oskouei et al. 2011; Shah et al. 2010; Shi et al. 2017; Turta and Singhal 2004; Zhao et al. 2014, 2013). Thus, steambased processes are not in line with the climate change mitigation strategies which have led oil industry into a search of best alternatives. One such alternative technology is the toe-to-heel air injection (THAI) process which is an in-situcombustion-type method that uses horizontal producer (HP) well in place of vertical one used in conventional in situ combustion (ISC) method (Greaves et al. 2005, 1999; Xia et al. 2002) to recovery upgraded oil. The THAI process does not possess any of the disadvantages of the conventional ISC. Rather, it falls into the group of the so-called short-distance displacement processes in which mobilised upgraded oil is produced immediately it drains down under the influence of gravity (Turta and Singhal 2004). This will lead to early realisations of return on investment and hence substantially lowering the exposure of oil businesses to the risks of the highly volatile oil market. Other advantages of the THAI process include (i) production of in situ heavy-torelatively-light upgraded oil, (ii) high energy efficiency as it generates its own heat by burning a small fraction of the immobile carbonaceous component of the heavy oils and bitumen, (iii) it can be made self-sustaining if waste heat is recovered with aim of running utilities, (iv) it has recovery factor of up to $85 \%$ OOIP as consistently shown by physical experiments, and (v) it can be converted to simultaneously thermal and catalytic upgrading process through emplacement of an annular layer of commercially industrially hydrotreating catalyst around the HP well, etc., (Ado 2021; Rabiu Ado 2017; Rabiu Ado et al. 2017; Xia and Greaves 2006, 2002).

The THAI process was piloted in the field and was operated at semi-commercial scale as well. These two operations were conducted in Canadian Athabasca tar sand by a company formerly referred to as Petrobank. The first THAI pilot project which was conducted in the Whitesands recorded only partial technical validation of the process at the field scale (Petrobank 2009, 2008, 2007). The process was found to operate in a high-temperature-oxidation (HTO) mode, produce large concentration of hydrogen of up to $8 \mathrm{~mol} \%$, produce upgraded oil of several API points above the initial native reservoir value, etc. (Turta et al. 2020). Economically however, lots of money were lost due to low oil production rates, excessive sand productions that led to many costly interventions, lack of well-detailed process design and operation procedures, lack of understanding of the complex physicochemical and fluid dynamics processes inside the reservoir. In fact, even the models used to simulate the process were not up-scaled to handle field-size calculations and provide physically meaningful predictions. To digress a little, the preceding last point cannot be stressed enough because systematically and theoretically based upscaling procedure developed by Ado (2020a,b) has shown that laboratory-scale validated model is incapable of predicting and thus cannot be used to predict, field-scale processes that are taking place inside the reservoir. However, due to being hopeful, Petrobank proposed two more THAI projects in Kerrobert and May River, respectively, at just the time 
when the Whitesands' project was stopped and considered completed. The May River project did not take place as it was cancelled. The Kerrobert THAI project was operated at semi-commercial scale with 12-well pairs all arranged in a direct line drive pattern. This was operated from 2011 up to, to the best of my knowledge, 2016 before it was declared by Touchstone, which took over the Petrobank, as uneconomical to continue with (Petrobank 2013, 2014; Touchstone 2015, 2016). Part of the failure was the inability of the operators to establish a well-structured combustion front. This could be due to air channelling into the bottom water that is underlying the Kerrobert bitumen reservoir. It could also be due to reservoir heterogeneity since the reservoir was found to have many large shales that might have impeded proper combustion front expansion. It should be noted that the concentration of produced oxygen was not high enough to justify a conjecture that air was bypassing the combustion zone. Oil production rates also were very low to the extent that Wei et al. (2020a, b) concluded that the THAI process is a low-oil-production-rate technology albeit that it is more energy-efficient than SAGD, they said. They also explained that there is an air injection rate limit above which no incremental gain in oil production rates can be realised. However, the low oil production rates might be caused due to the mobilised upgraded oil draining into the bottom water which is shown to be a thief zone (Ado 2020c). Furthermore, given that Petrobank had experienced excessive sand production that might have also hindered and thus limited the flow rates of the mobilised upgraded oil into the HP well, lack of understanding of physicochemical and fluid dynamics inside the reservoir could very well be to blame for the failure to establish the well-structured combustion front and to achieve high oil production rates. In fact, multiple studies (Ado 2020a, b; Kovscek et al. 2013; Nissen et al. 2015) have shown that laboratory-scale validated numerical models are incapable of predicting the physicochemical transport processes in field-scale reservoirs. However, what these studies did not observe and show are the differences especially in terms of reservoir flow dynamics between the laboratoryscale and the field-scale models. Given that the latter are necessary for successful process design and deployment, these differences must be fully delineated if optimal process operation is the ultimate target. The problem of low oil production rates in the THAI process might have also been caused by the mismatch between process stability in form of optimally well-structured combustion front leaning forward and oil recovery efficiency in which the mobilised upgraded oil flux vectors are slanted with backward-pointing and simultaneously partly downward-pointing heads. This is because if the shales surrounding the reservoirs are porous and permeable enough to allow mobilised upgraded oil to flow through them, then that could be the reason for low oil production rates in the actual reservoir. It could well be that the mobilised upgraded oil was continuously lost going in opposite direction away from the HP well and outside the pattern. However, to test this supposition, numerical models at laboratory and field scales are conducted and two-dimensional profiles having oil flux vectors at reservoir condition superimposed on them are compared. That is the main aim of this article. The other aim is to propose solution strategies so that all the mobilised upgraded oil is captured and produced.

\section{Reservoir models development}

In this work, both the experimental-scale (from here onward called E) and field-scale (from here onward called F) numerical models are composed of Canadian Athabasca bitumen and reservoir properties. The model $\mathrm{E}$ is similar to that developed by Rabiu Ado (2017) which he then validated against physical experimental results reported by Xia and Greaves (2002). Both models E and F are developed and simulated using the Computer Modelling Group (CMG) reservoir thermal simulator (i.e. the STARS). The dimensions of the models and the injector(s)/horizontal producer wells configurations can be seen in Fig. 1. However, because of the complexity of multi-components, multi-phase reactive transport processes through porous media, many input parameters must be specified so that the targeted performance parameters of the THAI process can be predicted. Likewise, the initial and boundary conditions must be specified. However, all of these information has already been reported in previous works which partly form part of Rabiu Ado's PhD thesis (2017). Nevertheless, the key input parameters are summarily shown subsequently.

\section{Petro-physical and reservoir initial parameters}

The Athabasca bitumen reservoir porosity, horizontal absolute permeability, absolute permeabilities ratio $k_{h} / k_{v}$, initial temperature and pressure, and initial oil, water, and gas saturations respectively as used in each model can be seen from Table 1. For more information about the selection of the laboratory-scale parameters which are validated against experimental results, see Rabiu Ado (2017) and Ado (2020d). The oil/water and gas/oil relative permeability curves as used in both models can be found in Rabiu Ado (2017) and Ado (2020d), and consequently, they are not repeated here in order to conserve space.

\section{Properties of the reservoir fluids and its rock}

The effective formation compressibility of the reservoir is $1.4 \times 10^{-5} \mathrm{kPa}^{-1}$. The reservoir fluids and its rock thermal

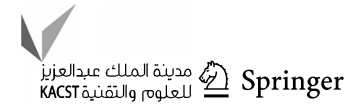


Fig. 1 Three-dimensional reservoir dimensions, injector(s)/ horizontal producer wells configurations in staggered line drive pattern, and the cardinal directions of $\mathbf{i}, \mathbf{j}$, and $\mathbf{k}$. a Is for model E (i.e. laboratory-scale model) and $\mathbf{b}$ is for model $F$ (i.e. field-scale model)

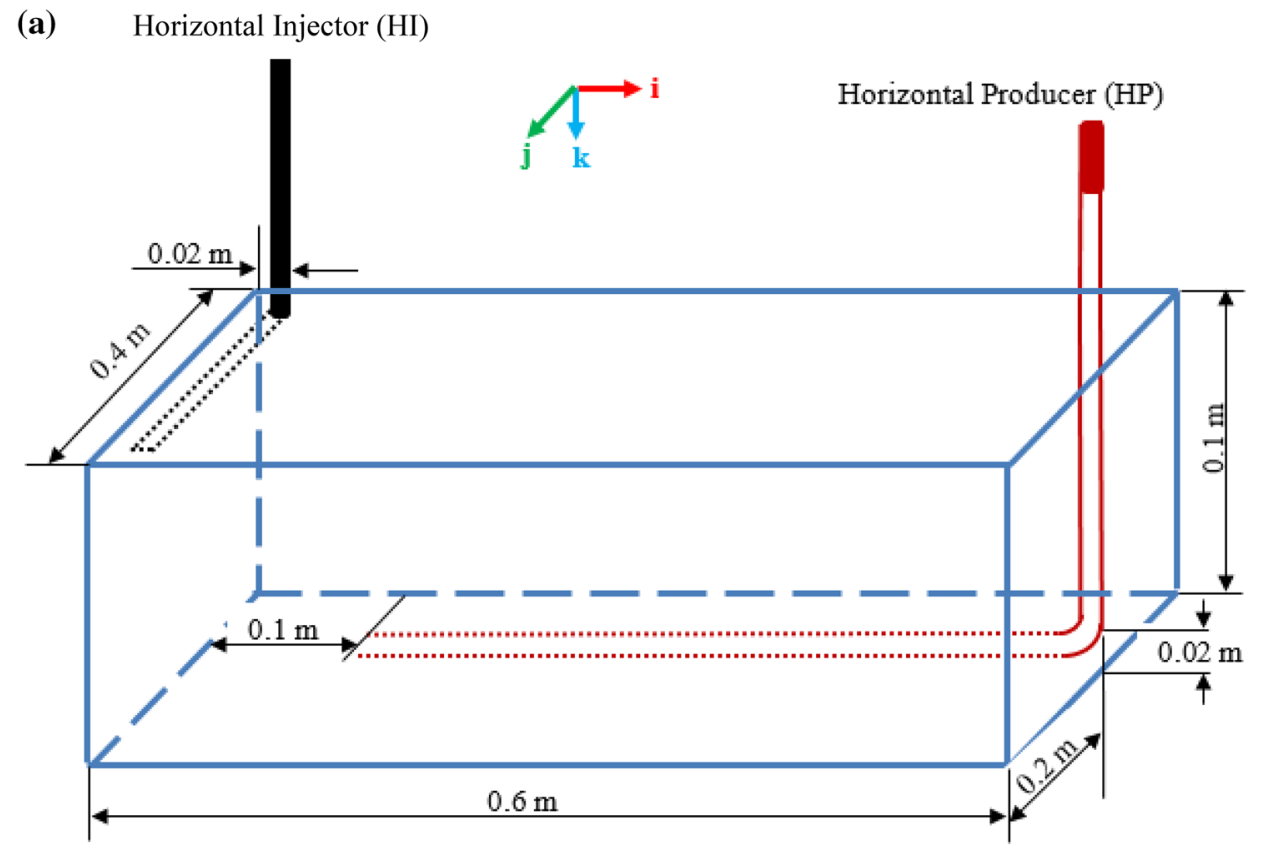

(b)

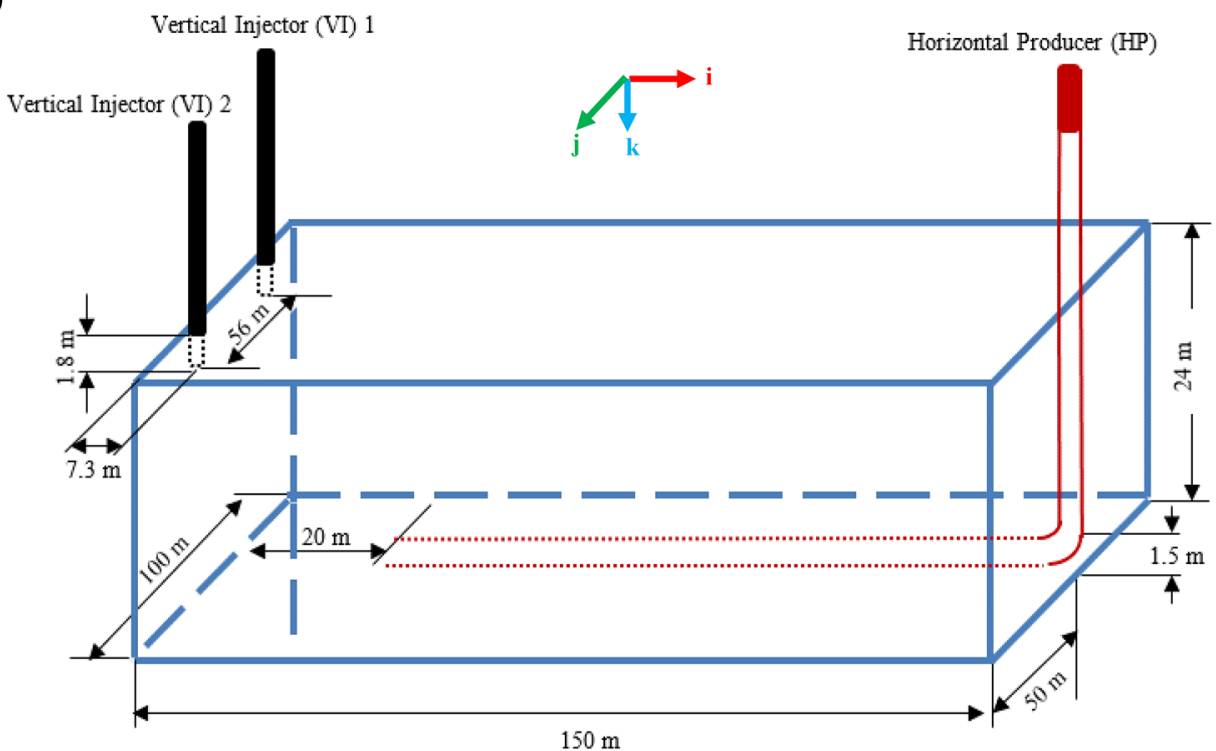

properties are given in Table 2. All of these variables are used in both the laboratory- and field-scale models.

\section{PVT properties of the Athabasca bitumen}

Bitumen is composed of so many compounds to the extent that it is impractical to characterise it based on all the individual components that combined to make it. As a consequence, oil pseudo-components which are typically made up of many compounds that fall within a specified boiling temperature range are used. In this work, the detailed validated pressure, volume, and temperature properties of each oil pseudo-component have been reported in the previous works (Rabiu Ado 2017; Rabiu Ado et al. 2018, 2017) and are not repeated here. Similarly, the mol\% of each oil pseudo-component is reported there. Likewise, the temperature-dependent viscosity and the temperature-and-pressure-dependent equilibrium $K$-values can be found there and hence are not repeated here.

\section{Kinetics schemes and their parameters}

The THAI process is reported to operate in a high-temperature-oxidation (HTO) mode where the dominant reactions are thermal cracking and coke combustion reactions. Thus, 
Table 1 Petro-physical and reservoir initial parameters

\begin{tabular}{lll}
\hline Reservoir property & $\begin{array}{l}\text { Laboratory- } \\
\text { scale values }\end{array}$ & Field-scale values \\
\hline Reservoir porosity & 0.34 & 0.34 \\
Horizontal absolute permeability, & 11,500 & 6400 \\
$\quad k_{h}(\mathrm{mD})$ & & \\
Absolute permeabilities ratio $k_{h} / k_{v}$ & 3.3333 & 1.8551 \\
Initial oil saturation, $S_{\mathrm{o}}$ & 0.85 & 0.80 \\
Initial water saturation, $S_{\mathrm{w}}$ & 0.15 & 0.20 \\
Initial gas saturation, $S_{\mathrm{g}}$ & 0.00 & 0.00 \\
Reservoir initial pressure $(\mathrm{kPa})$ & 290 & 2800 \\
Reservoir initial temperature $\left({ }^{\circ} \mathrm{C}\right)$ & 27 & 20 \\
\hline
\end{tabular}

Table 2 Reservoir fluids and its rock thermal properties

\begin{tabular}{ll}
\hline $\begin{array}{l}\text { Reservoir rock and its fluids thermal } \\
\text { properties }\end{array}$ & Values \\
\hline Heat capacity of rock & $2600 \mathrm{~kJ} \mathrm{~m}^{-3}{ }^{\circ} \mathrm{C}^{-1}$ \\
Thermal conductivity of rock & $458.3333 \mathrm{~J} \mathrm{~m}^{-1} \mathrm{~min}^{-1}{ }^{\circ} \mathrm{C}^{-1}$ \\
Oil thermal conductivity & $7.9861 \mathrm{~J} \mathrm{~m}^{-1} \mathrm{~min}^{-1}{ }^{\circ} \mathrm{C}^{-1}$ \\
Gas thermal conductivity & $3.4722 \mathrm{~J} \mathrm{~m}^{-1} \mathrm{~min}^{-1}{ }^{\circ} \mathrm{C}^{-1}$ \\
Water thermal conductivity & $37.1528 \mathrm{~J} \mathrm{~m}^{-1} \min ^{-1}{ }^{\circ} \mathrm{C}^{-1}$ \\
\hline
\end{tabular}

they must be specified as input parameters in each model. For model E, a validated laboratory-scale kinetics scheme with its parameters reported by Rabiu Ado (2017) and Rabiu Ado et al. (2017) which used Phillips et al. (1985) thermal cracking kinetics scheme for Athabasca bitumen is used.
Therefore, these are shown in Tables 3 and 4 even though the aforementioned references can be consulted for the extra details. For model F, field-scale frequency factors which are different from the laboratory-scale ones are used. These are shown in Tables 3 and 4 and can also be found in Rabiu Ado (2017) and Ado (2020a) where detailed information about how to calculate them based on sound theory is provided, and also, the assumptions in the calculations are explained there. However, to make it clearest, it is worth explaining more about the up-scaled frequency factors. Thus, in this work, the direct conversion kinetics scheme previously developed by Ado (2020a) in both the laboratoryand field-scale models is used. To reiterate, the only kinetics parameter that differs between the laboratory and field scales is the frequency factor which is mathematically shown to be scale-dependent due to the fact that the fuel availability in the laboratory scale is the same as that in the field scale, thereby making the Damkhöler number to be independent of the scales. These imply that

$(k \tau)_{\text {lab }}=(k \tau)_{\text {field }}$

where $k$ is the frequency factor and $\tau$ is the space-time which is the time taken for material to be reacted within a given grid block. Since the time to produce a given reservoir in the laboratory is many orders of magnitude lower than that in the actual field reservoir, the only way that the fuel availability and hence the Damkhöler number can be independent of the scales is if the frequency factor is scaled. That is why model $\mathrm{E}$ has different frequency factors compared to those of model F. This is despite the fact that they have the same reactions schemes and activation energies.
Table 3 Athabasca bitumen thermal cracking reactions and their Arrhenius kinetics parameters

\begin{tabular}{llll}
\hline $\begin{array}{l}\text { Bitumen pseudo-components } \\
\text { thermal cracking reactions }\end{array}$ & $\begin{array}{l}\text { Model E reactions fre- } \\
\text { quency factors }\left(\mathrm{min}^{-1}\right)\end{array}$ & $\begin{array}{l}\text { Model F reactions fre- } \\
\text { quency factors }\left(\mathrm{min}^{-1}\right)\end{array}$ & $\begin{array}{l}\text { Reactions activation } \\
\text { energies }\left(\mathrm{kJ} \mathrm{mol}^{-1}\right)\end{array}$ \\
\hline $\mathrm{IC} \rightarrow 2.0471 \mathrm{MC}$ & $3.822 \times 10^{20}$ & $8.186 \times 10^{16}$ & 239.01 \\
$\mathrm{MC} \rightarrow 0.4885 \mathrm{IC}$ & $3.366 \times 10^{18}$ & $7.209 \times 10^{14}$ & 215.82 \\
$\mathrm{MC} \rightarrow 2.3567 \mathrm{LC}$ & $1.132 \times 10^{15}$ & $2.425 \times 10^{11}$ & 184.88 \\
$\mathrm{LC} \rightarrow 0.4243 \mathrm{MC}$ & $1.524 \times 10^{15}$ & $3.264 \times 10^{11}$ & 180.45 \\
$\mathrm{IC} \rightarrow 77.4563 \mathrm{COKE}$ & $2.320 \times 10^{15}$ & $4.969 \times 10^{11}$ & 180.88 \\
\hline
\end{tabular}

Note that the activation energies are the same regardless of the model being laboratory scale or field scale

Table 4 Athabasca bitumen pseudo-components combustion reactions and their Arrhenius kinetics parameters

\begin{tabular}{|c|c|c|c|c|}
\hline $\begin{array}{l}\text { Athabasca bitumen pseudo-components combustion } \\
\text { reactions }\end{array}$ & $\begin{array}{l}\text { Model E frequency fac- } \\
\text { tors }(\mathrm{kPa} \text { min })^{-1}\end{array}$ & $\begin{array}{l}\text { Model } \mathrm{F} \text { frequency fac- } \\
\text { tors }(\mathrm{kPa} \text { min })^{-1}\end{array}$ & $\begin{array}{l}\text { Activation energy } \\
\left(\mathrm{kJ} \mathrm{mol}^{-1}\right)\end{array}$ & $\begin{array}{l}\text { Heat of } \\
\text { reaction } \\
\left(\mathrm{kJ} \mathrm{mol}^{-1}\right)\end{array}$ \\
\hline $\mathrm{IC}+98.869 \mathrm{O}_{2} \rightarrow 77.456 \mathrm{CO}_{1.947}+46.904 \mathrm{H}_{2} \mathrm{O}$ & $1.812 \times 10^{8}$ & $2.772 \times 10^{3}$ & 138.00 & $4.00 \times 10^{4}$ \\
\hline $\mathrm{MC}+49.069 \mathrm{O}_{2} \rightarrow 37.075 \mathrm{CO}_{1.947}+25.953 \mathrm{H}_{2} \mathrm{O}$ & $1.812 \times 10^{9}$ & $2.772 \times 10^{4}$ & 138.00 & $1.60 \times 10^{4}$ \\
\hline $\mathrm{LC}+32.025 \mathrm{O}_{2} \rightarrow 14.600 \mathrm{CO}_{1.947}+35.623 \mathrm{H}_{2} \mathrm{O}$ & $1.812 \times 10^{10}$ & $2.772 \times 10^{5}$ & 138.00 & $4.91 \times 10^{2}$ \\
\hline $\mathrm{COKE}+1.22 \mathrm{O}_{2} \rightarrow \mathrm{CO}_{1.875}+0.565 \mathrm{H}_{2} \mathrm{O}$ & $1.000 \times 10^{10}$ & $1.530 \times 10^{5}$ & 123.00 & $3.90 \times 10^{2}$ \\
\hline
\end{tabular}

Note that the activation energies are the same regardless of the model being laboratory scale or field scale 


\section{Boundary conditions}

Both models have no flow boundary condition assigned to them with the exception of the wells via which fluids are injected and produced respectively. The horizontal producer (HP) well in model $\mathrm{E}$ was assigned a minimum bottom hole pressure (BHP) of $170 \mathrm{kPa}$ and a maximum liquid production rate of $25 \mathrm{~cm}^{3} \mathrm{~min}^{-1}$ as the boundary conditions. The simulator automatically selects either one of them based on which targeted one is violated. In the case of model $\mathrm{F}$, $2800 \mathrm{kPa}$ and $60 \mathrm{Sm}^{3} \mathrm{~h}^{-1}$ are respectively assigned as the minimum BHP and maximum liquid production rate as the boundary conditions. In the case of the HI well of model E, for the first $30 \mathrm{~min}$, electrical heating was carried out at a rate of $2115 \mathrm{~J} \mathrm{~min}^{-1}$ per grid block before switching to an air injection rate of $8000 \mathrm{Scm}^{3} \mathrm{~min}^{-1}$ which was assigned for the first $160 \mathrm{~min}$ of combustion period before subsequently being increased to $10,667 \mathrm{Scm}^{3} \mathrm{~min}^{-1}$ for an additional time of $130 \mathrm{~min}$. In the case of model F, saturated steam at a pressure of $5500 \mathrm{kPa}$ and with a quality of $80 \%$ was injected at a rate of $495 \mathrm{bbl} \mathrm{day}^{-1}$ cold water equivalent (CWE) through the two VI wells for a period of 104 days before switching to air injection which is injected at a rate of $20,000 \mathrm{Sm}^{3}$ day $^{-1}$ for a period of 2 years. To initiate the combustion, electrical ignitor was used once air injection in both models are commenced. With regard to heat crossing the reservoir boundary in form of heat loss, conductive parameters are specified to account for that by assuming that the heat loss takes place via the overburden and underburden only. Furthermore, it is worth highlight at this stage that the CMG STARS models source terms (i.e. the injectors) either as line sources in which "wellbore frictional pressure drop and liquid holdup effects"' are neglected or using the discretised wellbore model option which is "suited where frictional pressure drop or liquid holdup effects are important' (CMG 2012). The first method was applied to the vertical injector (VI) wells of model $\mathrm{F}$ because only steam and air flowed through them. Similarly, the first method was applied to the horizontal injector (HI) well of model E because only air flowed through it.

Table 5 Grid blocks, their numbers, and the simulation run time

\begin{tabular}{llll}
\hline S no & Grid blocks & $\begin{array}{l}\text { Numbers of } \\
\text { grid blocks }\end{array}$ & Simulation run time \\
\hline 1 & Large grid blocks & 12,000 & $26 \mathrm{~min}$ \\
2 & Medium grid blocks & 19,000 & $1 \mathrm{~h} 8 \mathrm{~min}$ \\
3 & Small grid blocks & 38,500 & $3 \mathrm{~h}, 48 \mathrm{~min}$ \\
4 & Small dynamic grid blocks & 38,500 & $2 \mathrm{~h}, 24 \mathrm{~min}$ \\
5 & Smaller grid blocks & 50,000 & $5 \mathrm{~h}, 29 \mathrm{~min}$ \\
6 & Smaller dynamic grid & 50,000 & $2 \mathrm{~h}, 53 \mathrm{~min}$ \\
& blocks & & \\
\hline
\end{tabular}

\section{Selection of optimum grid-blocks dimensions}

Sensitivity analysis is thoroughly conducted as can be seen in Table 5, Figs. 2 and 3. It is found that for the laboratoryscale numerical model, a total of 38,500 grid blocks are sufficient to capture the dynamics of the combustion front and provide near accurate prediction of the key performance indicators of the THAI process, and as a result, small grid blocks can be used. Furthermore, to additionally enhance the computational time while ensuring the accuracy of the results is maintained, small dynamic grid blocks are used. The dynamic gridding option is a built-in function called DYNAGRID in the CMG STARS (CMG 2012). It dynamically changes from identifying the parent grid blocks and solving the algebraic equations based on them after meeting set criteria to identifying the child grid blocks when other conditions are met. For the full details, see the previous work of Rabiu Ado (2017).

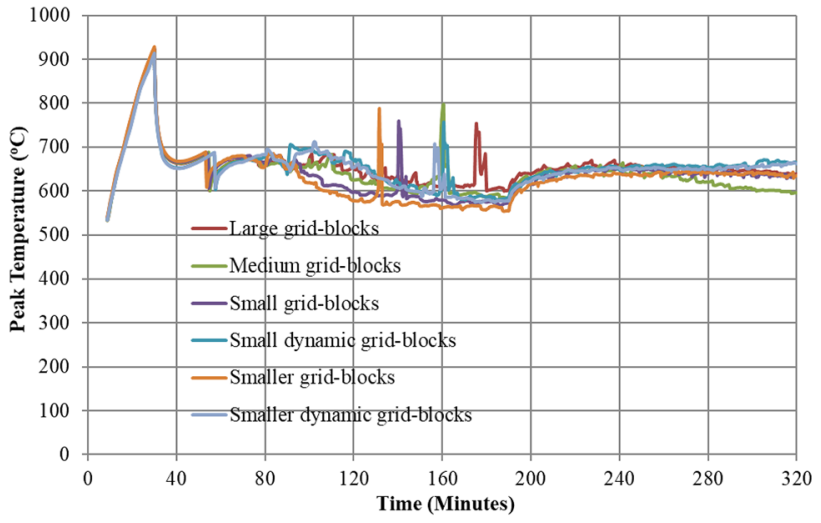

Fig. 2 Peak temperature as a function of time for the various gridblocks sizes

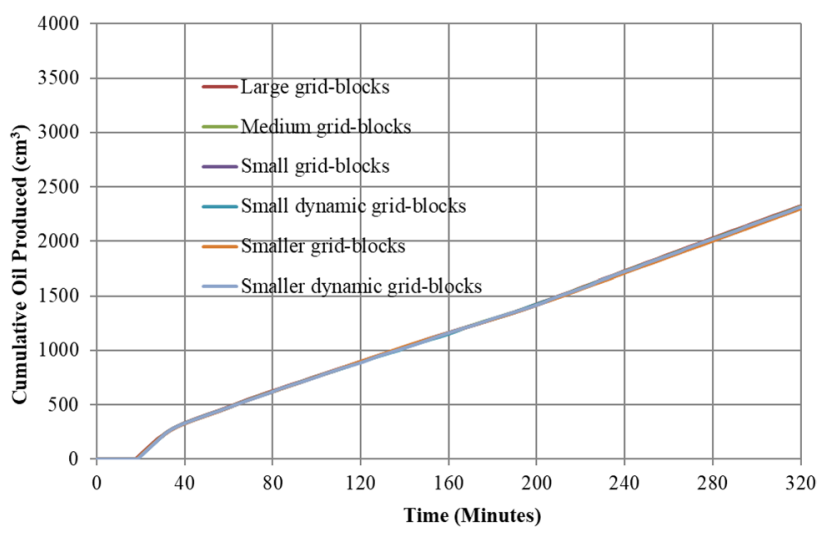

Fig. 3 Cumulative oil production as a function of time for the various grid-blocks sizes 
Note that the number of grid blocks in Table 5 is approximated to the nearest thousand except for the small and small dynamic grid blocks which are approximated to the nearest hundred.

In either model, the selected number of grid points in all the three respective directions is: 30 in the ith-direction $\times 19$ in the jth-direction $\times 7$ in the kth-direction. In order to fully capture the physics of the combustion front, the parent grid points in the ith- and jth-directions were, respectively, further discretised into 3 child grid points, thereby making the number of grid blocks in each model to be $90 \times 57 \times 7$ which is equal to 35,910 . However, to capture the transient nature of fluid, heat, and material transport in the horizontal producer (HP) well, a discretised wellbore model option called WELLBORE which is a built-in function available in the STARS software is used. The parent grid blocks to be discretised by the WELLBORE function are specified. Once discretised, the resulting grid blocks are then added to the reservoir grid blocks, thereby making the total number of grid blocks to be 38,500 which is in accordance with the previous studies (Ado et al. 2019; Rabiu Ado 2017). The resulting algebraic equations of the discretised reservoir and wellbore models are solved using parallel processing solver option referred to as PARASOL which used quad-core out of the computer's 16-core parallel processors. Furthermore, to repeat again, in order to minimise numerical diffusion, the small dynamic grid blocks are used. Also, the relative material balance error in each timestep was set to be $1 \times 10^{-5}$, thereby resulting in very small overall error at the end of the simulations.

\section{Summary of the solution method in the simulator}

The highly nonlinear PDEs that mathematically described the THAI process are usually discretised using central finite difference method with the time discretised using backward finite difference method so that a fully implicit solution is sought. The discretised basic mass conservation equations are solved together with the momentum conservation equations, energy balance, and phase constraint or mole fraction equations. The resulting fully implicit discretised equations are solved by the CMG STARS using the Newton's method.

\section{Results and discussion}

After successfully developing kinetics upscaling procedure based on sound theoretical calculations and simulating the THAI process at field scale, Rabiu Ado (2017) discovered that the dynamics of the processes in the reservoir are either (i) scale-dependent or (ii) that the validated laboratory-scale model showed that the process was operated in a pseudo-stable state or both. Given the field findings about the oil production rates in the THAI process being supposedly rather than justifiably low, it becomes apparent that the dynamics of the transport processes taking place inside the reservoir merit comprehensively detailed investigations. Accordingly, the experimental-scale model $\mathrm{E}$ will be studied first and then the field scale model $\mathrm{F}$ will come second before finally comparing them and drawing decisive conclusions. Doing so requires the two-dimensional profiles of some of the key parameters with oil flux vectors superimposed on them.

\section{Dynamics of oil production inside laboratory-scale combustion cell}

Temperature distribution profiles, especially in 2-dimensions, provide the extent of oxidation mode that is dominating the in-situ-combustion-type processes. From Fig. 4, it can be seen that at the two different times, the temperatures in the combustion zone are generally higher than $496{ }^{\circ} \mathrm{C}$, thereby implying that model $\mathrm{E}$ operates in the high-temperature-oxidation (HTO) mode which is in accordance with even field findings (Turta et al. 2020). This means that the rate of heat generation is high to the extent that thermal cracking, which takes place immediately downstream of the combustion zone but upstream of mobile oil zone (MOZ), is the dominant reaction that is resulting in coke deposition. The MOZ can be identified by the oil flux vectors at reservoir condition that are superimposed on the temperature (Fig. 4), oil saturation (Fig. 5), fuel or coke (Fig. 6), and oxygen (Fig. 7) profiles respectively. The larger the oil flux vectors, the higher the rate of mobilised oil draining and/or getting into the HP well. It is worth pointing out at this point that just ahead of the combustion front, there is the presence of immobile component which is the precursor to coke. However, since it is not in large concentration as shown in Fig. 6 and that the oil saturation there is less than 0.13 (Fig. 5), the oil flux vectors there are too small in size to the extent that they are not observable without excluding the larger vectors and/or having to zoom in the region. The MOZ is quite thick in length, and its thickness increases with time due to uninterrupted heat transfer combined with the advancement of the combustion front towards the heel of the HP well (i.e. by comparing Fig. 4a, b).

From the temperature distribution in the MOZ, regardless of the process time [i.e. at either $150 \mathrm{~min}$ (Fig. 4a) or $320 \mathrm{~min}$ (Fig. 4b)], four distinct areas can be identified. Similarly, from the oil saturation profiles (i.e. either Fig. 5a or b), also four distinct regions can be identified. The first which is closer to the combustion front has a temperature of at least $342{ }^{\circ} \mathrm{C}$ (Fig. 4), and that means the thermal cracking of the heavier immobile and small amount of moderately mobile component which in total have saturation of less than 0.13 (Fig. 5) is taking place there. That is the place where coke is deposited (see Fig. 6) which is then subsequently consumed by the advancing combustion front (Fig. 7). The second 
Fig. 4 Profiles showing temperature distribution at a $150 \mathrm{~min}$ and $\mathbf{b} 320$ min along the vertical middle plane. The superimposed arrows are oil flux vectors at reservoir condition. They indicate the location via which mobilised upgraded oil drains and enters into the HP well

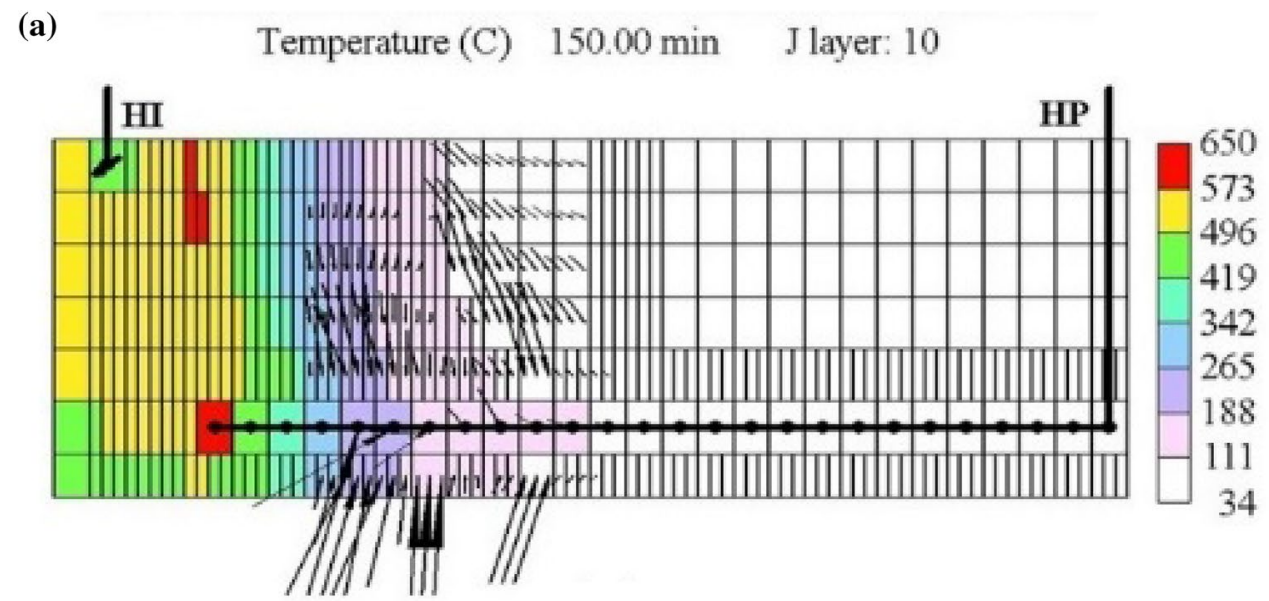

(b)

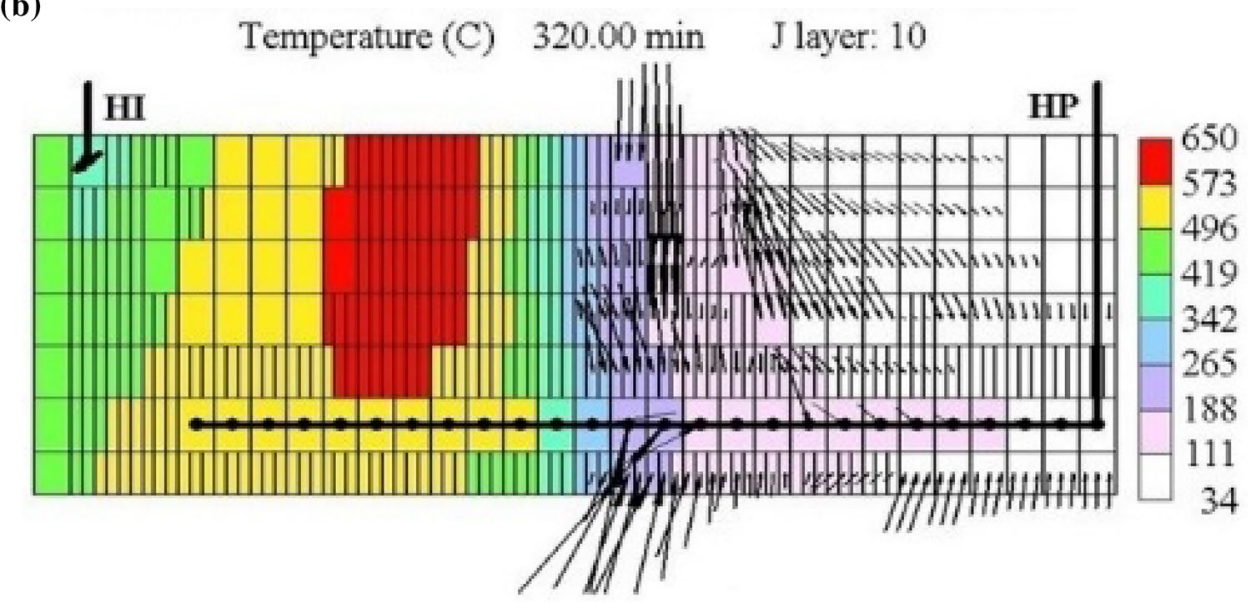

zone has a temperature range of 188 to $342{ }^{\circ} \mathrm{C}$ which indicates that mild thermal cracking of the relatively medium and light components is taking place in the zone. It has oil saturation ranging from 13 to $50 \%$, and it is the main zone where the oil flux vectors are largest which indicates intense gravity drainage and kinetic energy forced flow from below the HP well (Figs. 4, 5). The third zone is at a temperature range of between 111 and $188{ }^{\circ} \mathrm{C}$ (Fig. 4) and oil saturation range of $50 \%$ to $88 \%$ (Fig. 5) and it is the distillation zone. Therefore, in the distillation zone, the light components are driven out into vapour phase before condensing and mixing with the relatively low temperature oil in the leading edge of the mobile oil zone (MOZ). The MOZ is also characterised of having most of its vectors downward-directed but also inclined and partly pointing towards the heel of the HP well. In fact, some are even nearly horizontally pointing towards the heel of the HP well. These, again, are indications that the components leaving that zone are mostly lighter and in vapour phase. Then finally, there is the fourth region which has temperatures of lower than $111{ }^{\circ} \mathrm{C}$ and has oil saturations of greater than $88 \%$, and it is here that the gaseous hydrocarbons from the distillation region condense and mix with the relatively cold oil and drain under gravity. Figures 4 and 5 also show that oil production also takes place from below the HP well as indicated by the upward-directed vectors located in the bottom horizontal layer of the combustion cell. The driving force for oil flowing upward is the transfer of kinetic energy from oil draining from the vertical planes that are adjacent to the vertical middle plane. However, what is clearest from observing these profiles is that all of the head of the vectors are either totally vertically directed or slightly inclined and pointing towards the heel. None of them is pointing backward towards the toe of the HP well.

This could be for two reasons: (i) there is significant pressure drop between the MOZ and the heel of the HP well to the extent that rate of oil mobilisation is far lower than its production rate or that the producer back pressure is so low that large pressure force being transferred by combustion gases and draining oil has created a large pressure difference between the MOZ and the HP well; (ii) the concentration of laid down coke is so low that the combustion front propagated faster than it should, thereby becoming 
Fig. 5 Profiles showing oil saturation distribution at a $150 \mathrm{~min}$ and b 320 min along the vertical middle plane. The superimposed arrows are oil flux vectors at reservoir condition. They indicate the location via which mobilised upgraded oil drains and enters into the HP well

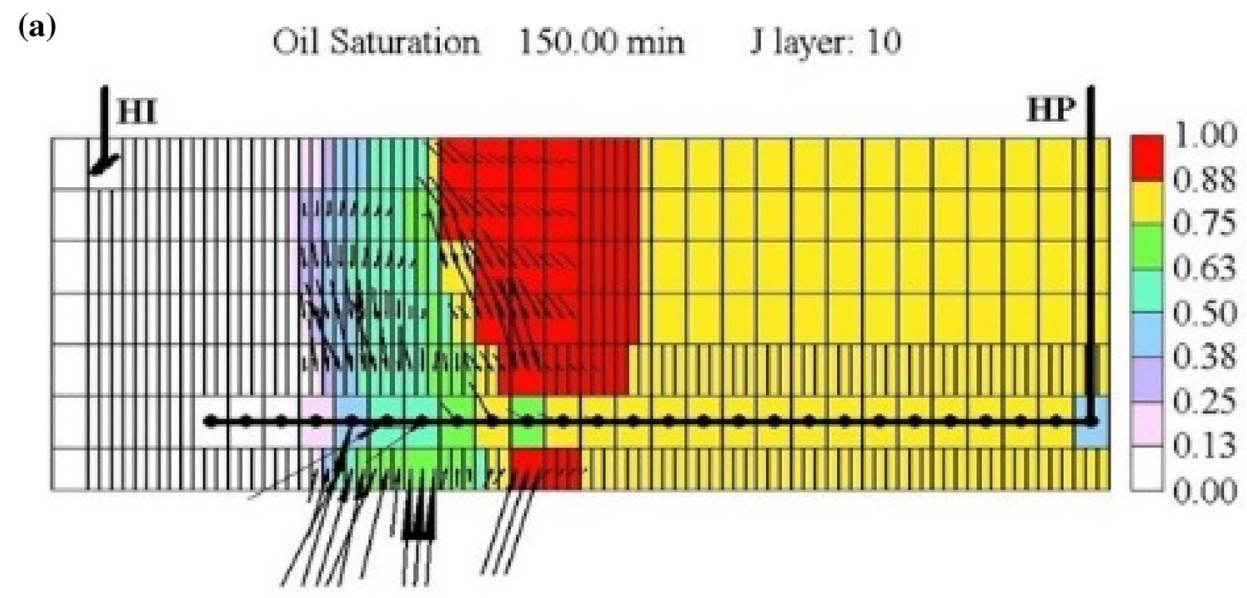

(b)

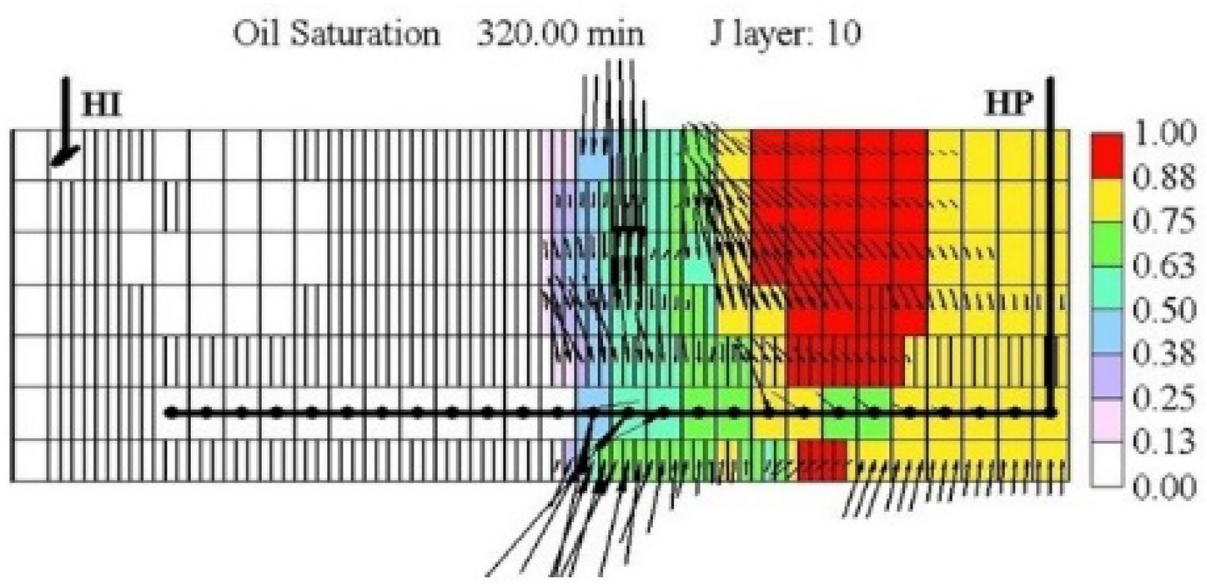

backward-leaning and leading near the base of the combustion cell (Figs. 6, 7). The latter is much more physically meaningful and hence is highly likely the case. Thus, it is apparent that oil drainage pattern in this laboratory-scale model $\mathrm{E}$ is efficient as all the mobilised upgraded oil, including from the base of the combustion cell, is produced as the combustion front advances in the toe-to-heel manner. However, the combustion front has a backward-leaning shape which is an indicator that it is propagating even inside the HP well. This implies that the process is operating in an unstable, inefficient, and unsafe mode in the sense that either the oxygen reaching the HP well will lead to excessive corrosion and hence well damage or that the combustion front will propagate up to the surface section of the HP well, thereby leading to well failure and hence uncontrollability of the fire front which could even lead to explosion. These two opposing patterns must be resolved to ensure healthy combustion front propagation in combination with efficient oil drainage and production rates are achieved. Consequently, suggested future studies to address these are given in "Comparison of flow patterns in the laboratory and field scales" section.

\section{Oil production dynamics inside field-scale reservoir}

To understand the oil drainage dynamics inside field-size reservoir, one vertical plane at the lateral edge of the reservoir, two vertical adjacent planes, and the vertical middle plane are considered (Fig. 8a-d). Observing all the 4 planes, it can be seen that most of the oil flux vectors, especially those at the upper horizontal planes and those in the mobile oil zone of the vertical middle plane (Fig. 8d), are nearly vertically downward-directed. However, there are some that are nearly horizontal with their heads pointing backward.

However, the rest of the oil flux vectors are downwarddirected but at angles such that they have both vertical and horizontal components. These latter ones can be described as similar to a ball rolling down an inclined plane with their horizontal components pointing to the lower edge of the plane and the vertical components pointing directly vertically downward. Thus, in all the planes, it is observed that the mobile oil zones (MOZs) at the upper layers lead those at the lower layers thereby making them as a whole slanting. On each vertical plane, especially the adjacent ones, the overall

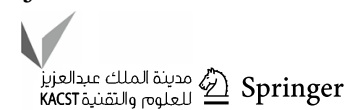


Fig. 6 Profiles showing fuel (or coke) distribution at a $150 \mathrm{~min}$ and b 320 min along the vertical middle plane. The superimposed arrows are oil flux vectors at reservoir condition. They indicate the location via which mobilised upgraded oil drains and enters into the HP well (a) Fuel Availability $(\mathrm{kg} / \mathrm{m} 3) \quad 150.00 \mathrm{~min} \quad J$ layer: 10

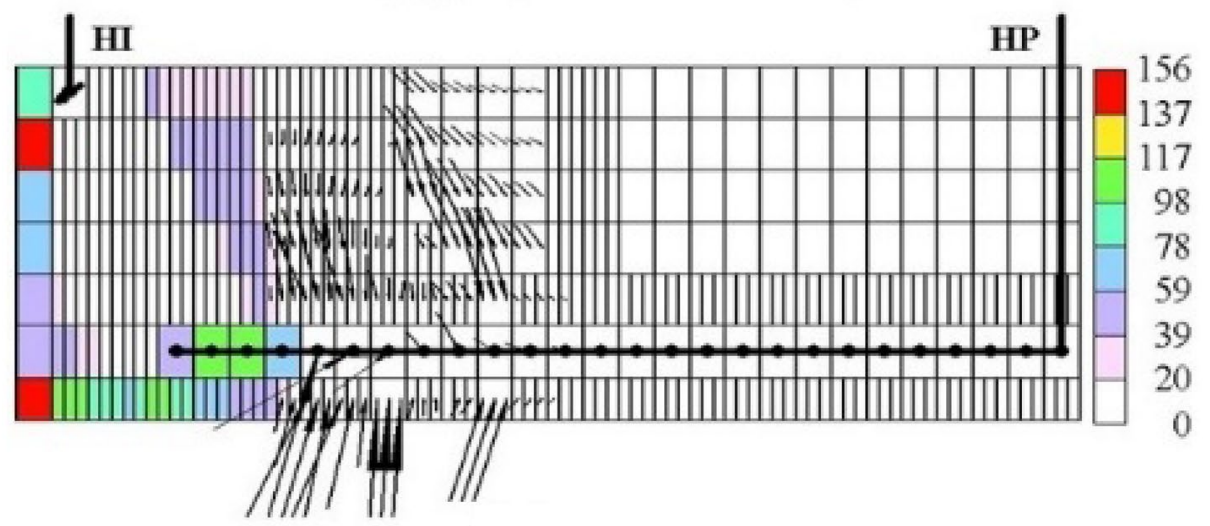

(b)

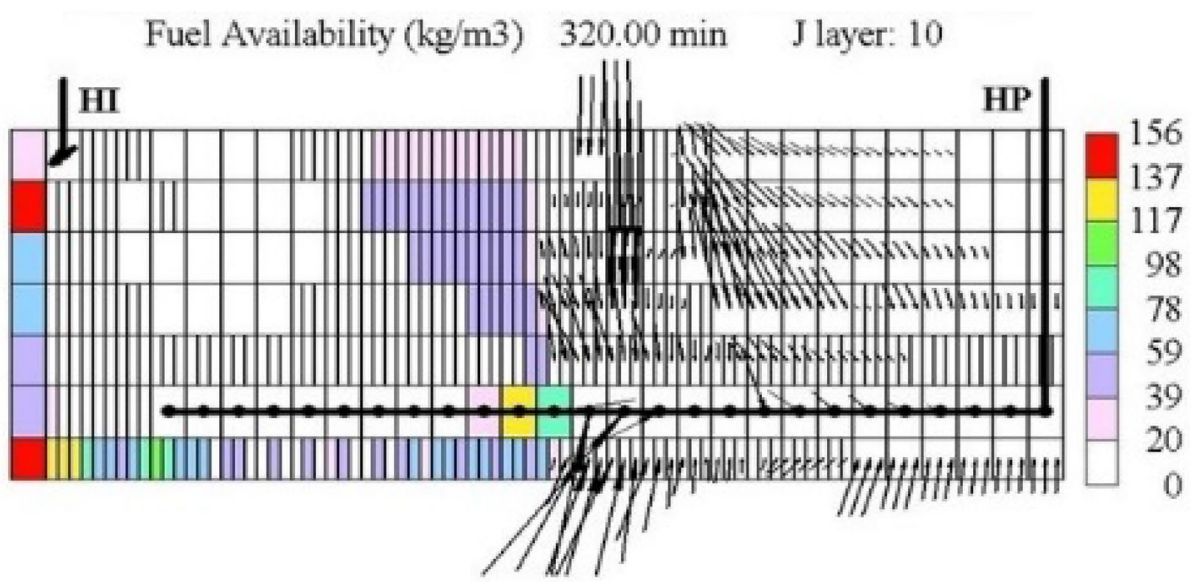

dynamic is that of oil draining down at an angle heading longitudinally in a heel-to-toe manner which is completely the opposite of the intended goal (i.e. to produce the mobilised upgraded oil in a toe-to-heel manner) of the process operation design. This hence implied that there must be a mechanism that has to change the flow direction of the mobilised oil to force it towards the HP well. Otherwise, only the mobilised upgraded oil closer to the vertical middle plane will drain into the HP well while those laterally far away from the vertical middle plane will be lost to porous and permeable shale surrounding the reservoir, which in turn will result in low oil production rates. Hence, to change the flow direction, the shale behind the toe of the HP well must be impermeable so that when the mobilised upgraded oil hits the rock, it will turn back due to its kinetic energy which it derived from the gravitational potential energy when it was draining. To further support the above interpretations, horizontal plane that is just above the bottom-most horizontal plane is shown in Fig. 9, and it can be seen that all the vectors are pointing backward at angle in the longitudinal direction of the HP well. The oil flux magnitude at reservoir condition indicates that high drainage rate takes place around and in the neighbourhood of the vertical middle plane where the HP well is located. Laterally at the two edges and their nearby areas, the oil mobilisation rate is quite low that the oil flux vectors did not appear there. Discussing about the afore-explained threeidentified drainage dynamics, it can be seen that the mobile oil zone (MOZ) that lies ahead of the combustion front has different thicknesses depending on the vertical plane it is on (Fig. 8). Similar conclusion can be derived from observing Fig. 9 as detailed just above. Therefore, for example, the lateral edge vertical plane (i.e. J-plane 1) has thicker MOZ than that in the J-plane 4 which in turn is thicker than that in the J-plane 7, etc., up to the vertical middle plane after which element of symmetry is seen with the J-plane 13 having the same dynamics as J-plane 7, etc.

Figure 10 shows that the largest oil flux vectors enter the HP well via its toe. This mobilised upgraded oil majorly comes from vertical planes adjacent to those at the two lateral edges as can be seen in Fig. 10a. Due to conversion of gravitational potential energy to kinetic energy and due to relatively small pressure difference, they intensely moved 
Fig. 7 Profiles showing oxygen distribution at a $150 \mathrm{~min}$ and b 320 min along the vertical middle plane. The superimposed arrows are oil flux vectors at reservoir condition. They indicate the location via which mobilised upgraded oil drains and enters into the HP well (a) Gas Mole Fraction(O2) $150.00 \mathrm{~min} \quad J$ layer: 10

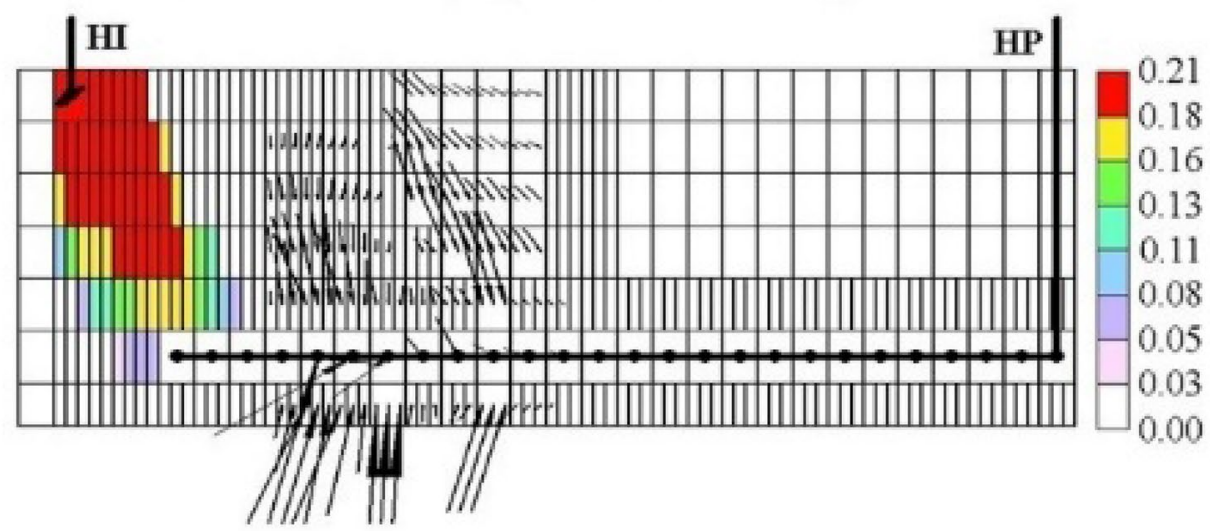

(b)

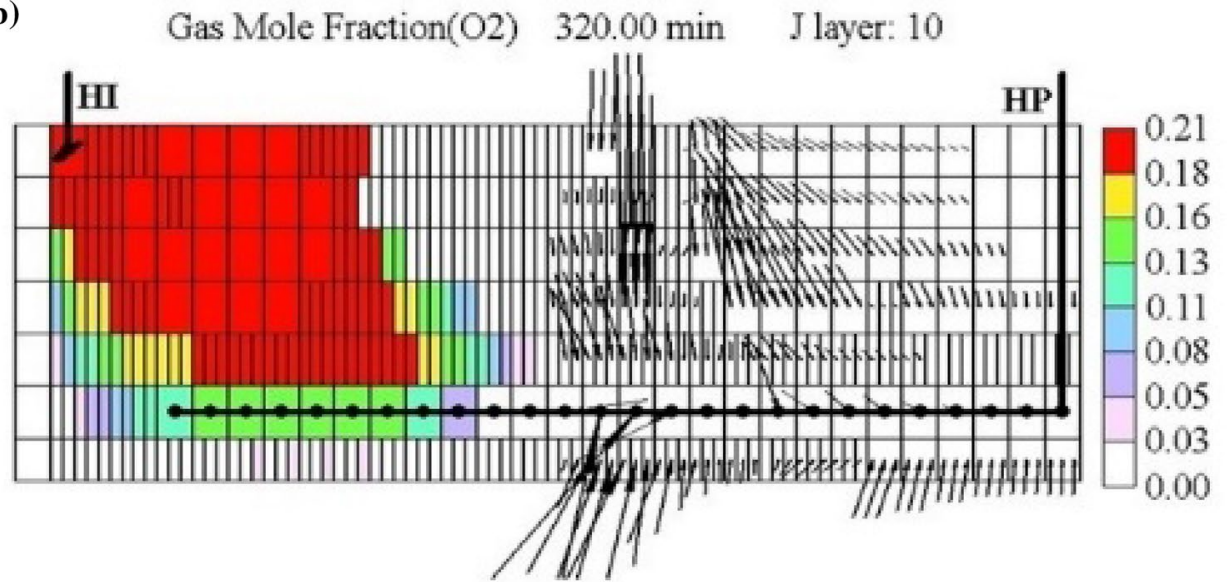

towards the toe after hitting the left longitudinal edge of the reservoir that is behind the toe of the HP well where no flow boundary condition is assumed in this study. Observing Fig. 10a carefully, it can be discerned that the toe location has the largest oil flux magnitude of between 1391 and 1546 $\mathrm{cm}^{3} \mathrm{~min}^{-1}$ (2.00 to $2.23 \mathrm{~m}^{3} \mathrm{day}^{-1}$ ). This is then followed by the area behind the toe region of the HP well and a zone ahead of the combustion front along the HP well where the magnitude of the oil flux in each of the two locations is up to $1237 \mathrm{~cm}^{3} \mathrm{~min}^{-1}\left(1.78 \mathrm{~m}^{3} \mathrm{day}^{-1}\right)$. This is a difference between the toe and the other locations by up to $20 \%$. This study has shown for the first time that there are actually two mobile oil zones: the one ahead of combustion front with lower oil flux magnitude (i.e. MOZ) and the one containing large pool of partially upgraded oil at the base of the reservoir just behind the toe of the HP well (Fig. 10a). Therefore, it is reasonably accurate to conclude that the relatively moderate oil rate entering the HP well in the MOZ that is located ahead of the combustion front comes from the vertical middle plane and its immediate adjacent vertical planes on its either side. However, the mobilised upgraded oil draining down at an angle from the vertical planes that are laterally at the two edges and their immediate adjacent ones is forced to flow down until it hits the no flow boundary behind the toe of the HP well at which locations it turns and gets into the well via the toe (Fig. 10b). Another critical finding in this study is the fact that within two years of the combustion period, the temperature of the mobilised upgraded oil around the toe of the HP well has reached up to $359{ }^{\circ} \mathrm{C}$, thereby leading to produce higher-temperature oil compared to that in the MOZ region. This finding is critical to in situ catalytic upgrading processes since an annular layer of catalyst can be emplaced around the toe of the HP well where temperatures are up to $359{ }^{\circ} \mathrm{C}$ to effect further upgrading via catalysis. This temperature is far higher than the catalyst bed temperature of $325^{\circ} \mathrm{C}$ used by Abu et al. (2015) to catalytically upgrade the Athabasca bitumen. In fact, in that study, substantial hydrodenitrogenation in combination with considerable increase in API gravity and decrease in viscosity was observed in both the dry and the wet modes of the in situ combustion coupled with in situ catalytic upgrading process.

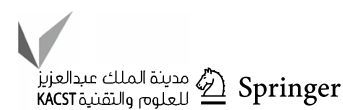




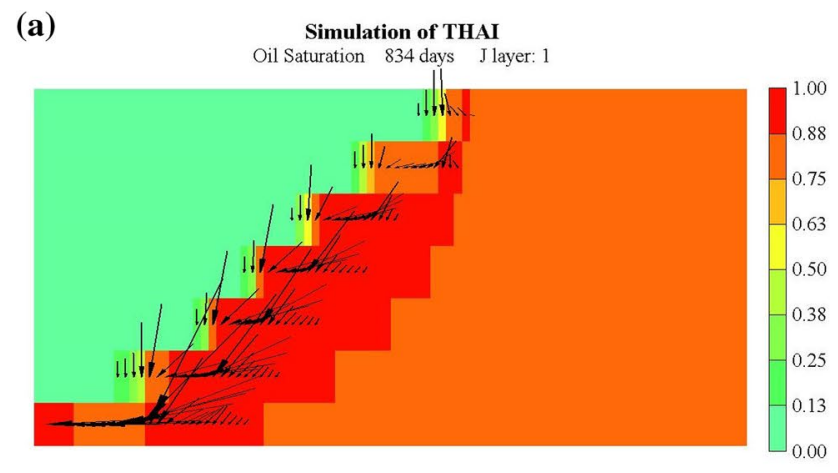

(c)

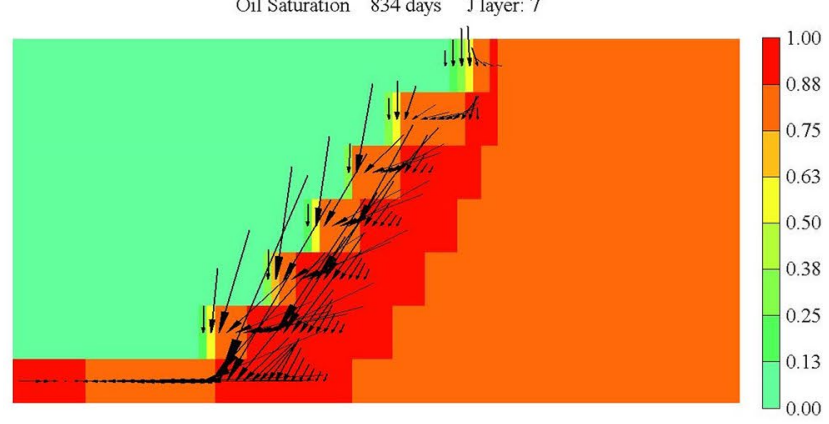

Fig. 8 Profiles showing oil saturation distribution for vertical planes at the a lateral edge (J-plane 1), b adjacent plane where VI 1 is located (J-plane 4), c adjacent plane which is 3-planes away from the middle plane (J-plane 7), and d middle plane where the HP well is

\section{Simulation of THAI}

Flux Oil Magnitude RC (cm3/min) 834 days $\quad$ K layer: 6
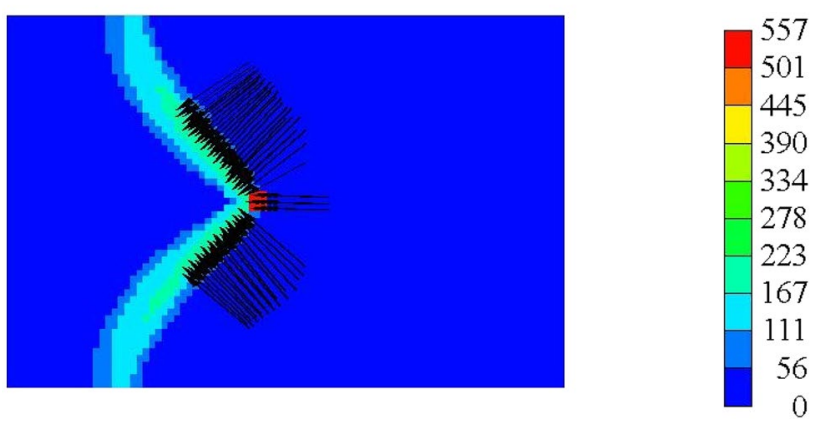

Fig. 9 Profiles showing oil flux magnitude distribution on a horizontal plane that is just overlying the bottom horizontal plane. The HP well is located at the bottom horizontal plane which directly underlies this one. The superimposed arrows are oil flux vectors at reservoir condition. They indicate the location via which mobilised upgraded oil drains and enters into the HP well or moves to behind the toe region of the HP well

In actual reservoir in the field, shale with very low permeability and porosity must be present behind the toe in order for the large pool of mobilised upgraded oil to be forced into the toe as we have just seen from the simulation. As a

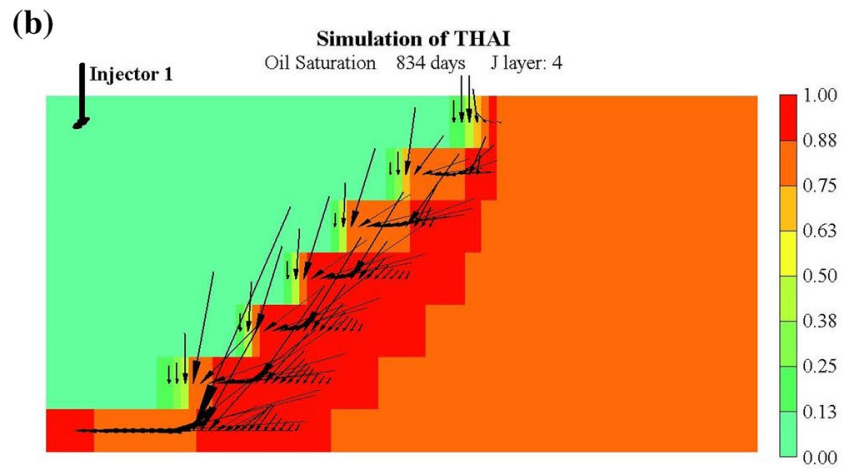

(d)

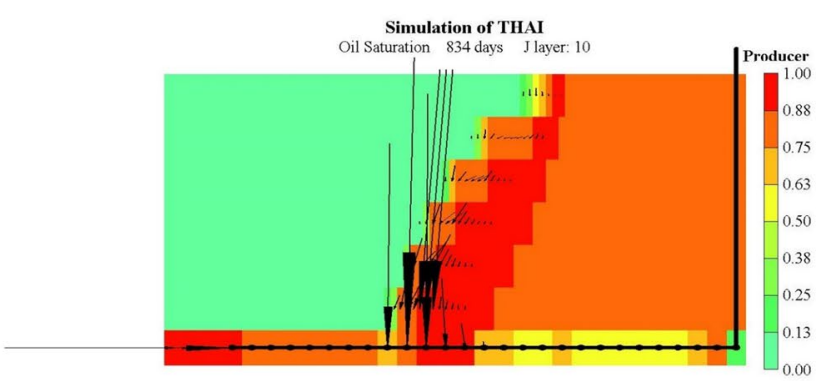

located (J-plane 10) of the reservoir. The superimposed arrows are oil flux vectors at reservoir condition. They indicate the location via which mobilised upgraded oil drains and enters into the HP well or moves to behind the toe region of the HP well

result, to have thorough design, there have to be multiple studies, for example, about (i) the ability of the shale in the toe region to transmit fluids outside the reservoir, (ii) optimum length of HP well so that the excessive sand production that might have also hindered the flow of oil from the MOZ into the HP well does not take place, (iii) cut-off time beyond which continuation of operation is either uneconomical or unsafe or both so that full dynamics of the reservoir can be conclusively understood, (iv) optimum HP wells spacing must be completely determined especially that this study has shown that oil draining from the vertical middle plane and its immediate adjacent planes is easily captured in the HP well which is unlike that from behind the toe, etc.

\section{Comparison of flow patterns in the laboratory and field scales}

To further enhance our understanding of the dynamics of the THAI process inside the reservoir, the conditions for combustion front stability and its efficient burning must first be outlined. At both scales (i.e. models $\mathrm{E}$ and F), the injector well (be it vertical or horizontal) is typically located in the top part of the reservoir as shown in Fig. 1. Steam or electrical heater is used to condition the outlet region of the injector well(s) in 
(a)

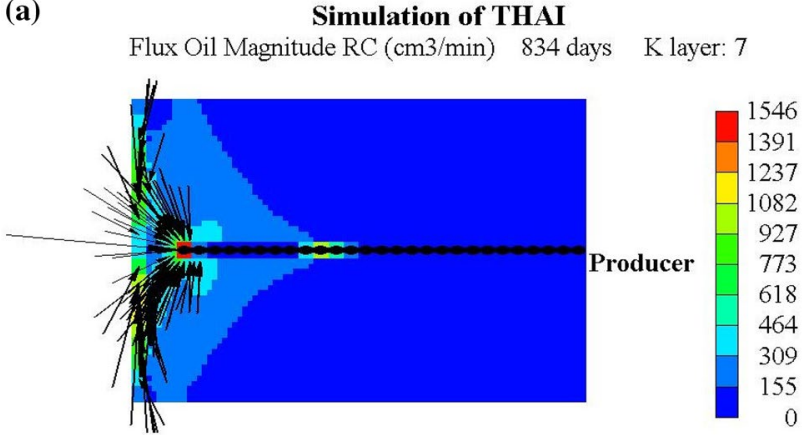

(b)

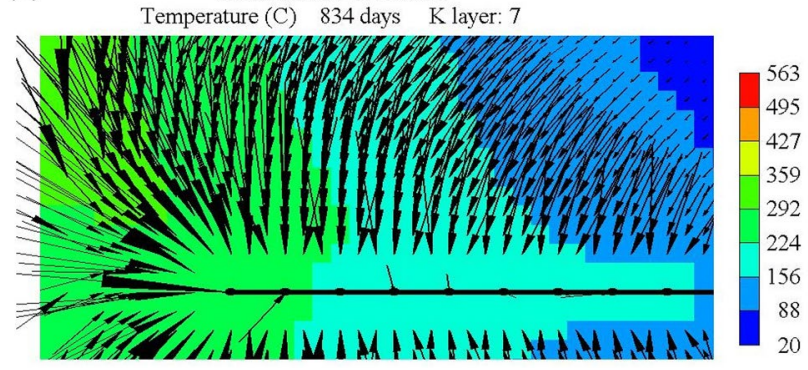

Fig. 10 a Profile showing oil flux magnitude distribution on the bottom horizontal plane where the HP well is located and over its whole axial length, and $\mathbf{b}$ is a profile showing temperature distribution on the zoomed in area of the toe of the HP well on the bottom horizontal plane. The superimposed arrows are oil flux vectors at reservoir condition. They indicate the location via which mobilised upgraded oil drains and enters into the HP well or moves to behind the toe region of the HP well

preparation for initiation of combustion. Therefore, the heat being added will have to travel both vertically downward and horizontally along the longitudinal direction (i.e. in a toe-toheel manner). Furthermore, the combustion is started at the outlet region of the injector(s) which implies that as it expands in the three direction, the front at the upper part of the reservoir will lead that at the lower portion of the reservoir. Thus, both the heat flow and advancement of combustion front will be tilted at an angle such that the lower regions lag the upper regions of the reservoir as both move in a toe-to-heel manner. This means it will take longer time before the combustion reaches the toe of the HP well and starts to propagate along the HP well which will result in premature oxygen production that could ultimately result in its early breakthrough. As a consequence, one of the key performance indicators for the stability and efficiency of the combustion in the THAI process is the shape of the combustion front. Longitudinally, if it is leaning forward with the top part leading while the bottom part is lagging, then it can be characterised as stable combustion front propagation which is exhibited by the field-scale model F. Finally, Fig. 6 shows that the laboratory-scale model has the combustion front at the lower portion of the reservoir leading while that at the upper part lags. In this case, the combustion front is backward-leaning and thus is unstable because it has already started propagating inside the HP well which can lead to early oxygen production leading to uneconomical or unsafe or both operating situation.

The above findings show that there is inconsistency about the goal of achieving large oil production rates with the propagation of stable, safe, and efficient combustion front. If the combustion is to be sustained optimally, then most of the mobilised upgraded oil might be lost going in the wrong direction. Therefore, how to adjust the conventional THAI process in order to have relatively larger oil production rates must be answered. Some of the ways that the author thought might help address that dilemma include: (i) use of two inline horizontal producers with two vertical injectors arranged in a staggered line drive configuration as shown in Fig. 11, while at the same time maintaining an optimally propagating combustion front. This will mean regardless of the direction with the highest oil drainage rates, the mobilised drained upgraded oil is going to be captured by either of the two HP wells, (ii) use of two HP wells on the same line with a single vertical injector in a direct line drive configuration as shown in Fig. 12 while simultaneously sustaining efficient, stable, and safe combustion front. However, this option ii will be prone to early oxygen production or breakthrough since all the wells are on the same plane and therefore the combustion front does not have to travel laterally before it can reach the toe of each HP well, (iii) decreasing the HP wells' lateral separation so that the distance between the vertical middle planes along the longitudinal direction, where there is relatively moderate oil drainage into the HP well, is reduced to take advantage of having multiple vertical middle planes and their immediate adjacent ones, so that most of the mobilised oil is captured, etc.

\section{Conclusion}

The technical and economic validities of the THAI process are yet to be fully realised even though it has been operated at laboratory, pilot, and semi-commercial levels. The findings from Canadian Kerrobert THAI project suggested that there is no proportionality between oil production and air injection rates. However, this conclusion was reached without having to dig deeper into the dynamics of the transport processes inside the reservoir given that simulation studies which are not about them have shown them to be different. In fact, for the first time, this study has found them to be both scale-dependent and operation-dependent. Oil flux vectors at reservoir condition were superimposed on multiple parameters distributed, respectively, on two-dimensional profiles. For the laboratory-scale numerical model E, what is clearest from observing the two-dimensional profiles is that all of the head of the vectors are either totally vertically directed or slightly inclined and pointing towards the heel. None of them is pointing backward towards the toe of the

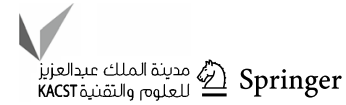


Fig. 11: Three-dimensional reservoir control volume which consists of two inline horizontal producers with two vertical injectors arranged in a staggered line drive configuration. The injectors are located at the top of the reservoir, $7 \mathrm{~m}$ offset distance away from the toe of each horizontal producer $\mathrm{P} 2 \mathrm{~A}$ and $\mathrm{P} 2 \mathrm{~B}$ respectively
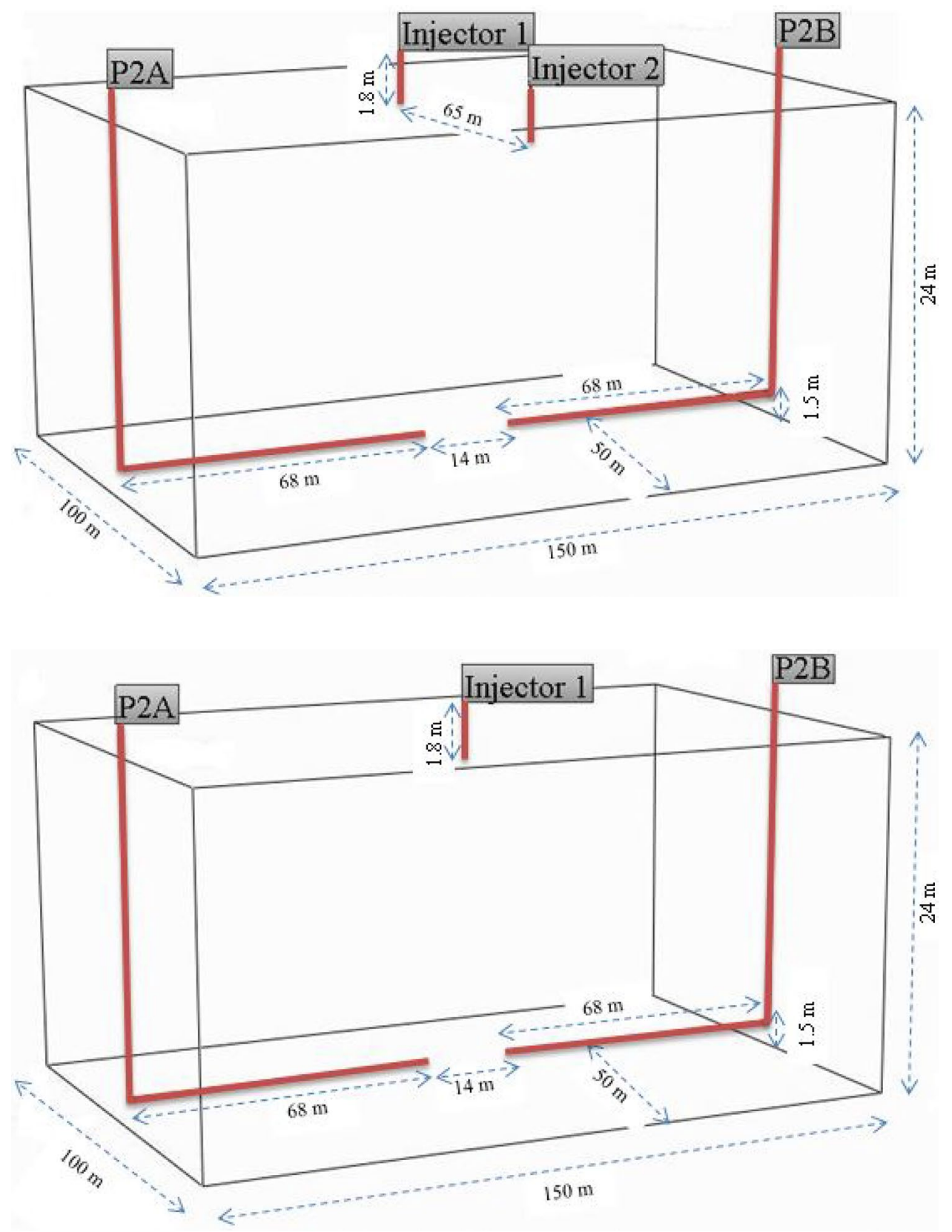

Fig. 12: Three-dimensional reservoir control volume which consists of two inline horizontal producers with a single vertical injector arranged in a direct line drive configuration. The injector is located at the top of the reservoir, $7 \mathrm{~m}$ offset distance away from the toe of each horizontal producer $\mathrm{P} 2 \mathrm{~A}$ and $\mathrm{P} 2 \mathrm{~B}$ respectively (1) 
for the large pool of mobilised upgraded oil to be forced into the toe as we have just seen from the simulation. As a result, to balance these two conflicting dynamics of combustion front going upward and longitudinally and the mobilised oil draining down towards the region behind the toe of the $\mathrm{HP}$ well at an angle, future studies are proposed in order to ensure thorough design and operation procedures are partly established. These include about studying (i) the ability of the shale in the toe region to or to not transmit fluids outside the reservoir, (ii) optimum length of HP well so that the excessive sand production that might have also hindered the flow of oil from the behind-the-toe mobile oil zone into the HP well does not take place, (iii) cut-off time beyond which continuation of operation is either uneconomical or unsafe or both so that full dynamics of the reservoir can be conclusively understood, (iv) optimum HP wells spacing must be completely determine especially that this study has shown that oil draining from the vertical middle plane and its immediate adjacent planes is easily captured in the HP well which is unlike that from behind the toe, (v) use of two inline horizontal producers with two vertical injectors arranged in a staggered line drive configuration as shown in Fig. 11. This will mean regardless of the direction with the highest oil drainage rates, the mobilised drained upgraded oil is going to be captured by either of the two HP wells, (vi) use of two HP wells on the same line with a single vertical injector in a direct line drive configuration as shown in Fig. 12 while simultaneously sustaining efficient, stable, and safe combustion front. However, this last option will be prone to early oxygen production or breakthrough.

Acknowledgements The author is gratefully acknowledging the Deanship of Scientific Research (DSR) at King Faisal University for financially supporting the publication of this work under the Nasher Track 2021 with research grant number of 216074 .

Funding The author is gratefully acknowledging the Deanship of Scientific Research (DSR) at King Faisal University for funding this work under the Nasher Track 2021 with a research grant number of 216074.

\section{Declarations}

Conflict of interest The author declares that there is no conflict of interest.

Open Access This article is licensed under a Creative Commons Attribution 4.0 International License, which permits use, sharing, adaptation, distribution and reproduction in any medium or format, as long as you give appropriate credit to the original author(s) and the source, provide a link to the Creative Commons licence, and indicate if changes were made. The images or other third party material in this article are included in the article's Creative Commons licence, unless indicated otherwise in a credit line to the material. If material is not included in the article's Creative Commons licence and your intended use is not permitted by statutory regulation or exceeds the permitted use, you will need to obtain permission directly from the copyright holder. To view a copy of this licence, visit http://creativecommons.org/licenses/by/4.0/.

\section{References}

Abu II, Moore RG, Mehta SA, Ursenbach MG, Mallory DG, Pereira Almao P, Carbognani Ortega L (2015) Upgrading of Athabasca bitumen using supported catalyst in conjunction with in-situ combustion. J Can Pet Technol 54:220-232. https://doi.org/10.2118/ 176029-PA

Ado MR (2020a) A detailed approach to up-scaling of the Toe-toHeel Air Injection (THAI) In-Situ Combustion enhanced heavy oil recovery process. J Pet Sci Eng. https://doi.org/10.1016/j. petrol.2019.106740

Ado MR (2020b) Predictive capability of field scale kinetics for simulating toe-to-heel air injection heavy oil and bitumen upgrading and production technology. J Pet Sci Eng. https://doi.org/ 10.1016/j.petrol.2019.106843

Ado MR (2020c) Simulation study on the effect of reservoir bottom water on the performance of the THAI in-situ combustion technology for heavy oil/tar sand upgrading and recovery. SN Appl Sci. https://doi.org/10.1007/s42452-019-1833-1

Ado MR (2020d) Impacts of kinetics scheme used to simulate toe-toheel air injection (THAI) in situ combustion method for heavy oil upgrading and production. ACS Omega. https://doi.org/10. 1021/acsomega.9b03661

Ado MR (2021) Improving oil recovery rates in THAI in situ combustion process using pure oxygen. Upstream Oil Gas Technol. https://doi.org/10.1016/j.upstre.2021.100032

Ado MR, Greaves M, Rigby SP (2019) Numerical simulation of the impact of geological heterogeneity on performance and safety of THAI heavy oil production process. J Pet Sci Eng. https:// doi.org/10.1016/j.petrol.2018.10.087

British Petroleum (BP) (2020) Statistical review of world energy. https://www.bp.com/content/dam/bp/business-sites/en/global/ corporate/pdfs/energy-economics/statistical-review/bp-statsreview-2020-full-report.pdf. Accessed 16 Nov 2020

CMG (2012) Advanced process and thermal reservoir simulator. Calgary, Alberta, Canada

Gates ID (2010) Solvent-aided Steam-Assisted Gravity Drainage in thin oil sand reservoirs. J Pet Sci Eng 74:138-146. https://doi. org/10.1016/j.petrol.2010.09.003

Gates ID, Larter SR (2014) Energy efficiency and emissions intensity of SAGD. Fuel 115:706-713. https://doi.org/10.1016/j.fuel. 2013.07.073

Greaves M, El-Sakr A, Xia TX, Ayasse C, Turta A (1999) Thainew air injection technology for heavy oil recovery and in situ upgrading. Annu Tech Meet. https://doi.org/10.2118/99-15

Greaves M, Xia TX, Ayasse C (2005) Underground upgrading of heavy oil using THAI- "toe-to-heel air injection". https://doi. org/10.2118/97728-MS

Kovscek A, Castanier L, Gerritsen M (2013) Improved predictability of in-situ-combustion enhanced oil recovery. SPE Reserv Eval Eng 16:172-182

Liu Z, Wang H, Blackbourn G, Ma F, He Z, Wen Z, Wang Z, Yang Z, Luan T, Wu Z (2019) Heavy oils and oil sands: global distribution and resource assessment. Acta Geol Sin Engl Ed 93:199212. https://doi.org/10.1111/1755-6724.13778

Ma Z, Leung JY (2020) Efficient tracking of solvent chamber development during warm solvent injection in heterogeneous reservoirs via machine learning. SPE Canada Heavy Oil Conf. https://doi.org/10.2118/199917-MS

Meyer RF, Attanasi ED, Freeman PA (2007) Heavy oil and natural bitumen resources in geological basins of the world. U.S. Geological Survey Open-File Report 2007-1084. http://pubs.usgs. gov/of/2007/1084/

Mokrys IJ, Butler RM (1993) In-situ upgrading of heavy oils and bitumen by propane deasphalting: the vapex process. SPE Prod Oper Symp. https://doi.org/10.2118/25452-MS

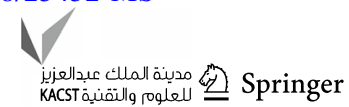


Nissen A, Zhu Z, Kovscek A, Castanier L, Gerritsen M (2015) Upscaling kinetics for field-scale in-situ-combustion simulation. SPE Reserv Eval Eng 18:158-170

Paitakhti Oskouei SJ, Moore RG, Maini B, Mehta S (2011) Feasibility of in-situ combustion in the SAGD chamber. J Can Pet Technol 50:31-44

Petrobank (2007) IETP 01-019 whitesands experimental project-2007 annual report. https://open.alberta.ca/dataset/06f18b06-855645ee-a654-3ff50f 25f4f5/resource/4a1bc69b-6d92-4583-a50352d36ccaeba9/download/ietp-no.-01-019-whitesands-pilot-econo mics-2007-annual-report.pdf. Accessed 24 Feb 2021

Petrobank (2008) IETP 01-019 whitesands experimental project-2008 annual report. https://open.alberta.ca/dataset/06f18b06-855645ee-a654-3ff50f25f4f5/resource/49c917de-7190-45a1-b92e334b72a9aa67/download/01-019-ietp-report-with-title-page.pdf. Accessed 24 Feb 2021

Petrobank (2009) IETP 01-019 whitesands experimental projectfinal/annual 2009 report. https://open.alberta.ca/dataset/06f18 b06-8556-45ee-a654-3ff50f25f4f5/resource/8c557fe6-b2a5-44cbb58d-a27188a67731/download/ietp-approval-01_019-final-and2009-report.pdf. Accessed 24 Feb 2021

Petrobank (2013) Petrobank reports Q2 2013 financial results and operational update. http://www.petrobank.com/news. Accessed 20 May 2014

Petrobank (2014) Petrobank announces Q1 2014 financial and operating results. http://www.petrobank.com/news. Accessed 20 May 2014

Phillips CR, Haidar NI, Poon YC (1985) Kinetic models for the thermal cracking of athabasca bitumen: the effect of the sand matrix. Fuel 64:678-691

Rabiu Ado M (2017) Numerical simulation of heavy oil and bitumen recovery and upgrading techniques. University of Nottingham, Nottingham

Rabiu Ado M, Greaves M, Rigby SP (2017) Dynamic simulation of the toe-to-heel air injection heavy oil recovery process. Energy Fuels. https://doi.org/10.1021/acs.energyfuels.6b02559

Rabiu Ado M, Greaves M, Rigby SP (2018) Effect of pre-ignition heating cycle method, air injection flux, and reservoir viscosity on the THAI heavy oil recovery process. J Pet Sci Eng. https://doi.org/ 10.1016/j.petrol.2018.03.033

Shah A, Fishwick R, Wood J, Leeke G, Rigby S, Greaves M (2010) A review of novel techniques for heavy oil and bitumen extraction and upgrading. Energy Environ Sci 3:700-714. https://doi.org/ $10.1039 / \mathrm{b} 918960 \mathrm{~b}$
Shi L, Xi C, Liu P, Li X, Yuan Z (2017) Infill wells assisted in-situ combustion following SAGD process in extra-heavy oil reservoirs. J Pet Sci Eng 157:958-970. https://doi.org/10.1016/j.petrol.2017. 08.015

Touchstone (2015) Touchstone announces 2015 third quarter results and elimination of net debt; Updates trinidad acquisition. http:// www.touchstoneexploration.com/files/6136.November132015Q32015Results-FINAL-Formatted(002).pdf. Accessed 9 May 2016

Touchstone (2016) Touchstone announces kerrobert saskatchewan disposition. http://www.touchstoneexploration.com/files/6149. January20,2016-KerrobertDisposition-FINAL.pdf. Accessed 9 May 2016

Turta A, Singhal A (2004) Overview of short-distance oil displacement processes. J Can Pet Technol 43:PETSOC-04-02-02

Turta A, Kapadia P, Gadelle C (2020) THAI process: determination of the quality of burning from gas composition taking into account the coke gasification and water-gas shift reactions. J Pet Sci Eng 187:106638. https://doi.org/10.1016/j.petrol.2019.106638

Wei W, Rezazadeh A, Wang J, Gates ID (2020a) An analysis of toe-toheel air injection for heavy oil production using machine learning. J Pet Sci Eng. https://doi.org/10.1016/j.petrol.2020.108109

Wei W, Wang J, Afshordi S, Gates ID (2020b) Detailed analysis of toe-to-heel air injection for heavy oil production. J Pet Sci Eng 186:106704. https://doi.org/10.1016/j.petrol.2019.106704

Xia TX, Greaves M (2002) Upgrading Athabasca tar sand using toeto-heel air injection. J Can Pet Technol 41:7. https://doi.org/10. 2118/02-08-02

Xia T, Greaves M (2006) In situ upgrading of Athabasca tar sand bitumen using Thai. Chem Eng Res Des 84:856-864. https://doi.org/ 10.1205/cherd.04192

Xia TX, Greaves M, Turta AT (2002) Injection well—producer well combinations in THAI "toe-to-heel air injection". https://doi.org/ 10.2118/75137-MS

Zhao DW, Wang J, Gates ID (2013) Optimized solvent-aided steamflooding strategy for recovery of thin heavy oil reservoirs. Fuel 112:50-59. https://doi.org/10.1016/j.fuel.2013.05.025

Zhao DW, Wang J, Gates ID (2014) Thermal recovery strategies for thin heavy oil reservoirs. Fuel 117:431-441. https://doi.org/10. 1016/j.fuel.2013.09.023

Publisher's Note Springer Nature remains neutral with regard to jurisdictional claims in published maps and institutional affiliations. 